\title{
RELATO DE EXPERIÊNCIA EM ESTÁGIO CURRICULAR NÃO OBRIGATÓRIO DE INVERNO EM FISIOTERAPIA NO HOSPITAL SÃO JOSÉ DE CRICIÚMA
}

Joice de Abreu Brandolfi ${ }^{1}$, Nathaly Willemann Medeiros ${ }^{1}$, Maria Argentina de Souza Iens ${ }^{2}$, Évelin Vicente ${ }^{1}$

\section{INTRODUÇÃO}

Atualmente, estamos passando por uma transição em âmbito de saúde e aspectos epidemiológicos, alguns paradigmas vem sendo questionados, e o atendimento multiprofissional em ambiente hospitalar vem sendo cada vez mais efetivo.

Tendo em vista isso, a inserção do profissional fisioterapeuta em ambiente hospitalar, cresce diariamente, pois constitui enorme benefício para a prevenção de complicações no quadro do paciente, além de atuar na redução do tempo de internação, reduzindo os gastos em saúde pública.

O papel dos profissionais da área da saúde, em especial do fisioterapeuta, torna-se cada vez mais complexo face à constante qualificação dos serviços de assistência à saúde, que não se limitam mais a garantir sobrevida, mas a oferecer qualidade de vida às pessoas (MACHADO, 2006).

Entretanto, ainda se é pouco elucidada qual importância do fisioterapeuta em hospitais que realizam procedimentos de grande complexidade, como unidade de terapia intensiva (UTI), cirurgias neurológicas, ortopédicas, oncologia, dentre outros. Eles desenvolvem assistência humanizada e especializada, visando a recuperação do paciente (NAKAGAWA, 2006).

Para Pollock (2003) a importância da fisioterapia vai do aspecto assistencial a redução do custo financeiro: o tratamento de pacientes em fase de recuperação, seja de traumas ou cirurgias, resulta em uma maior agilização das altas, o que aumenta a rotatividade dos leitos, diminui as chances de infecções hospitalares, minimiza os custos com remédios e oxigênio, e, principalmente, fornece uma melhor qualidade de vida ao paciente.

\footnotetext{
${ }^{1}$ Universidade do Extremo Sul Catarinense, Santa Catarina, Brasil.

${ }^{2}$ Hospital São José, Criciúma, Santa Catarina, Brasil.
} 


\section{METODOLOGIA}

Trata-se de um relato de experiência baseado no período de vigência do estágio curricular não obrigatório em fisioterapia hospitalar de inverno no Hospital São José, onde quatro acadêmicos previamente selecionados por meio de um edital, foram designados para participar da experiência em âmbito hospitalar. O estágio ocorrera no período matutino entre as $08 \mathrm{~h}$ e $12 \mathrm{~h}$, com uma carga horária semanal de 20h, no período de 08 a 29 de julho de 2016. Os atendimentos foram realizados nos seguintes setores que abrangem o hospital: Unidade Santa Clara, Clínica São Francisco, Pronto Socorro Leitos, Clínica Cirúrgica Masculina/Feminina, Unidade Santa Bárbara e Unidade de Oncologia 01.

Inicialmente, discutiu-se em grande grupo os objetivos e perspectivas gerais e individuais da realização do estágio, posteriormente iniciaram-se os atendimentos, primeiramente em duplas e depois de forma individual com supervisão, baseada no Procedimento Operacional Padrão (POP), desenvolvido pelos gestores da instituição.

Os diagnósticos previamente estabelecidos e evidências clínicas eram consultados, depois se elaborava uma estratégia de intervenção e posteriormente era feita a atuação fisioterapêutica nos pacientes sob internação. Utilizou-se dos recursos da fisioterapia motora e respiratória, com manobras de higiene brônquica e estímulo de tosse quando se fazia necessário. Após os atendimentos, eram feitas as respectivas evoluções, de forma eletrônica. Fez-se um registro do total de atendimentos realizados pelos acadêmicos nesse período, através do sistema Philips Tasy (PT) que promove a gestão e organização dos serviços de saúde, utilizado pelo HSJ. Pela sua complexidade e variabilidade de processos, os hospitais necessitam de um sistema de gestão que possa facilitar o fluxo de informações entre todos os setores da instituição e integrar pessoas, processos e informações. A partir da integração promovida pelo (PT), o hospital tem a garantia da confiabilidade das informações.

As informações, cadastradas uma única vez no sistema, evitam o retrabalho e garantem a segurança e rastreabilidade, subsidiando a tomada de decisão em todos os níveis gerenciais, incluindo o processo de reconhecimento e formulação de estratégias de intervenção baseadas em evidências clínicas.

Estipulou-se uma média de tempo para os atendimentos fornecidos, assim como traçou-se um perfil das principais incidências patológicas decorrentes no hospital. Os atendimentos supervisionados contaram com demonstrações explicativas da realização de manobras e intervenções para promoção de higiene brônquica, como a aspiração. Sendo que 
os acadêmicos também realizaram e assistiram tais procedimentos, de acordo com a complexidade do quadro clínico dos pacientes.

Durante o período de estágio, foram feitas trocas de experiências e impressões individuais e coletivas sobre humanização e atenção holística no atendimento ao paciente crítico.

\section{RESULTADOS}

Evidencia-se a importância da fisioterapia em ambiente hospitalar, pela presença de pacientes em fase aguda, que necessitam de orientação, assim como dos acompanhantes/cuidadores. A fase aguda de intervenção merece atenção especial, pois é nela que serão delineados os contornos da reinserção do indivíduo ao seu ambiente e às atividades de vida diárias (AVD's). A fase crônica também demanda cuidados, e deve ser acompanhada pelo profissional fisioterapeuta em todos os aspectos, atenuando sua incidência e prezando pela diminuição e prevenção contra complicações.

O estágio realizado pelos acadêmicos proporcionou 206 atendimentos no período estipulado anteriormente, sendo que destes foram intervenções apenas com fisioterapia respiratória, intervenções com fisioterapia motora e com ambas. O tempo médio de atendimento oscilou entre 15 e 25 minutos, levando-se em consideração o quadro do paciente, e qual o tipo de intervenção se fazia necessária, após diagnóstico fisioterapêutico cinéticofuncional.

Encontra-se o contraste entre o tempo de sessão na prática clínica (que dura em média de 30 a 45 minutos) e da fisioterapia hospitalar, pois o perfil do paciente é diferente, e deve-se prevenir e evitar a fadiga, que pode levar a complicações no quadro de internação.

Entre as principais intervenções realizadas, os quadros clínicos mais observados neste período foram: AVE isquêmico, pós-operatório de fratura de colo de fêmur (em idosos), pósoperatório de cirurgia de revascularização do miocárdio e neoplasias em diferentes tecidos.

Os principais recursos da fisioterapia respiratória e motora utilizados incluíram: manobras de higiene brônquica, aspiração por via oral e via traqueostomia, mobilização de secreção, proporção de pressão expiratória positiva (PEEP) utilizando selo d'água, ventilação não invasiva através do BIPAP - Bilevel Positive Airway Pressure (com os parâmetros selecionados de acordo com as características individuais dos pacientes). Exercícios assistidos, ativo-assistidos e passivos, através da mobilização de grandes articulações, bem 
como exercícios metabólicos, fortalecimento muscular, alongamento, aumento da amplitude de movimento $(\mathrm{ADM})$, propriocepção, treino de marcha e orientações gerais, tanto ao paciente quanto aos familiares presentes, para um retorno com qualidade de vida às AVD's.

\section{CONCLUSÕES}

Portanto, conclui-se que a atuação do profissional fisioterapeuta em ambiente hospitalar, é de grande importância, pois a intervenção é fundamental na prevenção de complicações. O estágio temporário proporcionou uma nova visão do perfil clínico dos pacientes críticos e também dos pacientes dos demais setores de internação, pois trouxe aos acadêmicos uma percepção crítica e diferenciada da atuação do profissional fisioterapeuta nesse campo de trabalho. Promovendo a associação da teoria vista em sala de aula com a realidade vivenciada na prática clínica do hospital. Ampliando os conhecimentos e o feedback com relação às intervenções realizadas.

\section{AGRADECIMENTOS}

Agradeço à minha família, que sempre me ensinou que a Educação é quem abre as portas para a liberdade.

\section{REFERÊNCIAS}

BOTELHO, V. R.; ABGUSSEN, C. M. B.; MACHADO, G. C. F. P.; ELIAS, A. J. R.; BENEDITO-SILVA, A. A.; BITTENCOURT, L. R. A. et al. Epidemiologia do trauma raquimedular cervical na zona norte de São Paulo. Arq Bras Neurocir, v. 20, n. 3, p. 64-76, 2001.

CARUSO, F. C. R. Análise da variabilidade da frequência cardíaca durante uma sessão de fisioterapia em um paciente com insuficiência cardíaca crônica na fase I da reabilitação cardiovascular. Fisioterapia Brasil, Rio de Janeiro, v. 11, n. 1 , p.67-69, fev. 2010.

CRUZ, T. S.; RODRIGUES, F.; BELETTINI, N. P.; CERETTA, L. B.; COELHO, B. L. P.; TUON, L. Diagnóstico de saúde e atuação do fisioterapeuta nas unidades básicas de saúde Health diagnosis and physical therapy performance in basic health units. Fisioterapia Brasil, Rio de Janeiro, v. 11, n. 6, p.438-443, dez. 2010.

DI MAMBRO, T. R.; PASCHOALINO, F. J. Fisioterapia no paciente oncológico: relato de uma experiência hospitalar. Fisioterapia em Movimento, Curitiba, v. 13, n. 1, p. 29$36,2000$.

KAIZER, A. A. S. Análise da eficiência da aplicabilidade do tratamento cinético-funcional no processo de reabilitação do trabalhador. FisioBrasil, Rio de Janeiro, v. 12, n. 96 , p. 69, 2009. 
MACHADO, M. G. R. Bases da fisioterapia respiratória: terapia intensiva e reabilitação. Rio de Janeiro: Guanabara Koogan, 2008.

MEYER, F.; VIALLE, L. R.; VIALLE, E. N.; BLEGGI-TORRES, L. F.; RASERA, E.; LEONEL, I. Alterações vesicais na lesão medular experimental em ratos. Acta Cir Bras, v. 18, n. 3, p. 203-8, 2003.

NAKAGAWA, N. K.; BARNABÉ, V. Fisioterapia do sistema respiratório. São Paulo: Sarvier, 2006.

POLLOCK, M. L.; SCHMIDT, D. H. Doença cardíaca e reabilitação. 3 ed. Rio de Janeiro: Revinter, 2003.

SIMONI, R. F.; LEITE, M. R.; FÓFANO, R.; GIANCOLI, M.; CANGIANI, L. M. Hiperreflexia autonômica em gestante tetraplégica. Relato de caso. Rev Bras Anestesiol, v. 53, n. 4, p. 481-8, 2003. 